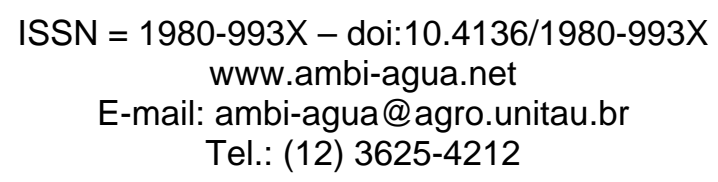

\title{
Desempenho do irrigâmetro no manejo da irrigação no Perímetro Irrigado do Jaíba, MG, Brasil \\ (doi:10.4136/ambi-agua.181)
}

\section{Ednaldo Miranda de Oliveira; Rubens Alves de Oliveira; André Leonardo Tavares de Paula; Júlio César Machado Baptestini; Samuel Petraccone Caixeta; Luan Brioschi Giovanelli}

\author{
Universidade Federal de Viçosa - UFV, Departamento de Engenharia Agrícola - DEA \\ E-mail: ednaldoufv@yahoo.com.br; rubens@ufv.br; andreirriga@yahoo.com.br; jcbaptestini@yahoo.com.br; \\ samuel.caixeta@ufv.br; luanbg22@hotmail.com
}

\section{RESUMO}

Objetivou-se neste trabalho determinar o coeficiente do irrigâmetro $\left(\mathrm{K}_{\mathrm{I}}\right)$, assim como avaliar o desempenho do irrigâmetro utilizado no manejo da irrigação do girassol. O experimento foi conduzido no Perímetro Irrigado do Jaíba, em Jaíba, MG, a $15^{\circ} 36^{\prime}$ de latitude Sul e $43^{\circ} 42^{\prime}$ de longitude Oeste, com altitude de $460 \mathrm{~m}$. Na avaliação de desempenho do irrigâmetro ajustado nas alturas 1, 2, 3, 4, 5 e $6 \mathrm{~cm}$ do nível de água no evaporatório, comparou-se a evapotranspiração estimada pelo aparelho e a evapotranspiração de referência, calculada pelo método padrão de Penman-Monteith FAO 56 (Allen et al., 1998). Concluiu-se então que os valores de $K_{\mathrm{I}}$ obtidos foram 0,42 , 0,69, 0,85, 1,07, 1,34 e 1,61 para alturas dos níveis de água do evaporatório iguais a 1, 2, 3, 4, 5 e $6 \mathrm{~cm}$, respectivamente. Não houve diferença significativa entre a produtividade do girassol irrigado no período diurno, e irrigado no período noturno, sendo encontradas médias superiores que na literatura. O irrigâmetro mostrou-se satisfatório no manejo da irrigação e para obter a estimativa da evapotranspiração de referência nas condições climáticas da região, recomendase a utilização do aparelho equipado com evaporatório ajustado no nível 3,7 cm.

Palavras-chave: Agricultura irrigada; produtividade do girassol; eficiência de irrigação.

\section{Performance of the irrigameter in management of irrigation in the Jaíba Irrigated Perimeter, MG, Brazil}

\section{ABSTRACT}

The objective of this study was to determine the coefficient of irrigameter device (KI) and to assess its performance in the irrigation of sunflower. The experiment was conducted in the Jaíba Irrigated Perimeter, Jaíba, MG, located at $15^{\circ} 36^{\prime} \mathrm{S}$ and $43^{\circ} 42^{\prime} \mathrm{W}$, with an altitude of $460 \mathrm{~m}$. For the evaluation of the performance of the irrigameter, the water level in the evaporimeter was kept at 1, 2, 3, 4, 5 and $6 \mathrm{~cm}$ high, and the evapotranspiration estimated by the irrigameter was compared to the reference evapotranspiration, calculated by the standard method Penman-Monteith FAO 56 (Allen et al., 1998). It was concluded that the values of KI obtained were $0.42,0.69,0.85,1.07,1.34$ and 1.61 for the water levels in the evaporimeter corresponding to $1,2,3,4,5$ and $6 \mathrm{~cm}$, respectively. There was no significant difference between the yield of sunflower crop irrigated during day or night time; higher average values then reported by the literature were found. The irrigameter device was found to be satisfactory for irrigation control. To estimate the reference evapotranspiration in similar regions with similar climatic conditions, it is recommended to use the unit with evaporimeter adjusted to the level $3.7 \mathrm{~cm}$.

Keywords: irrigated agriculture, productivity of sunflower, irrigation efficiency. 
OLIVEIRA, E. M.; OLIVEIRA, R. A.; PAUlA, A. L. T.; BAPTESTINI, J. C. M.; CAIXETA, S. P.; GIOVANELLI, L. B. Desempenho do irrigâmetro no manejo da irrigação no Perímetro Irrigado do Jaíba, MG, Brasil. Ambi-Agua, Taubaté, v. 6, n. 1, p. 157-164, 2011. (doi:10.4136/ambi-agua.181)

\section{INTRODUÇÃO}

A outorga e a cobrança pelo uso da água limitam a quantidade de água a ser captada e induzem ao melhor controle da irrigação. O valor econômico atribuído à água aumenta o custo de produção, promovendo a busca pelo melhor controle da irrigação (Beskow et al., 2008). O uso eficiente da água na irrigação apresenta importância para reduzir o custo de energia elétrica, evitar doenças por umidade excessiva ou mesmo a lixiviação de nutrientes.

Na região norte de Minas Gerais, o clima quente e seco com reduzido índice pluviométrico faz com que a água seja utilizada intensamente para a irrigação. A energia elétrica gasta com a técnica da irrigação tem grande representatividade no custo da produção, principalmente no perímetro irrigado do Jaiba, onde também é cobrada a água devido ao seu custo de distribuição. Situações essas que fazem aumentar a importância do uso racional da água para viabilizar economicamente a agricultura irrigada (Sato et al., 2007).

Entretanto, somente a melhoria do sistema de irrigação não garante o uso eficiente da água, pois é preciso conhecer a quantidade de água necessária a ser aplicada. Nesse contexto, com a finalidade de simplificar o manejo da irrigação, Oliveira et al. (2008) desenvolveram o Irrigâmetro, o qual simplifica a interpretação das informações envolvidas no manejo da irrigação.

O Irrigâmetro (Figura 1) apresenta grande potencial de uso na agricultura irrigada, pois, além de ser de operação simples e de mais baixo custo de aquisição, se comparado a outros equipamentos para manejo de irrigação, ele fornece resposta prática às duas perguntas básicas do manejo de irrigação: quando e quanto irrigar?. Assim, o irrigante não precisa ter conhecimentos técnicos especializados sobre irrigação. De acordo com os resultados obtidos por Oliveira et al. (2007a), Oliveira et al. (2007b), Oliveira et al. (2008), Tagliaferre (2006, 2007), o Irrigâmetro pode ser usado para estimar a evapotranspiração de qualquer cultura, em qualquer estádio de desenvolvimento, para um valor de coeficiente de cultura (Kc) desejado.

O aparelho é equipado com um reservatório denominado evaporatório, construído de material plástico, contendo água com superfície exposta à atmosfera. O reservatório possui seção transversal cônica que permite variar a área exposta à atmosfera, de acordo com o nível de água no seu interior, possibilitando, de maneira versátil, obter diretamente a evaporação, a evapotranspiração de referência ou a evapotranspiração da cultura nos estádios I (inicial), II (desenvolvimento), III (florescimento) ou IV (final) de desenvolvimento (Oliveira e Ramos, 2008).

A estimativa do consumo de água das culturas pelo Irrigâmetro, nos diferentes estádios de desenvolvimento das plantas, baseia-se na variação do nível da água no evaporatório do equipamento. Na fase inicial de desenvolvimento, o nível da água no evaporatório é o mais baixo, em razão do menor consumo de água da cultura nesse período. A fase de florescimento caracteriza-se pelo maior consumo de água pela cultura durante o ciclo, sendo o nível de água no evaporatório o mais alto (Contin, 2008).

Por ser inovador e recente, existem poucas informações disponíveis sobre esta tecnologia. $\mathrm{O}$ coeficiente do Irrigâmetro $\left(\mathrm{K}_{\mathrm{I}}\right)$, utilizado para ajustar o aparelho às necessidades hídricas das culturas agrícolas, deve ser determinado para regiões com diferentes condições climáticas.

Na busca de parâmetros técnicos para aplicação desta tecnologia no Perímetro Irrigado do Jaíba, objetivou-se determinar o coeficiente do Irrigâmetro $\left(\mathrm{K}_{\mathrm{I}}\right)$ com base na evapotranspiração estimada pelo método de Penman-Monteith FAO 56 (Allen et al., 1998) e avaliar o seu desempenho no manejo da irrigação na cultura do girassol. 
OLIVEIRA, E. M.; OLIVEIRA, R. A.; PAUlA, A. L. T.; BAPTESTINI, J. C. M.; CAIXETA, S. P.; GIOVANELLI, L. B. Desempenho do irrigâmetro no manejo da irrigação no Perímetro Irrigado do Jaíba, MG, Brasil. Ambi-Agua, Taubaté, v. 6, n. 1, p. 157-164, 2011. (doi:10.4136/ambi-agua.181)

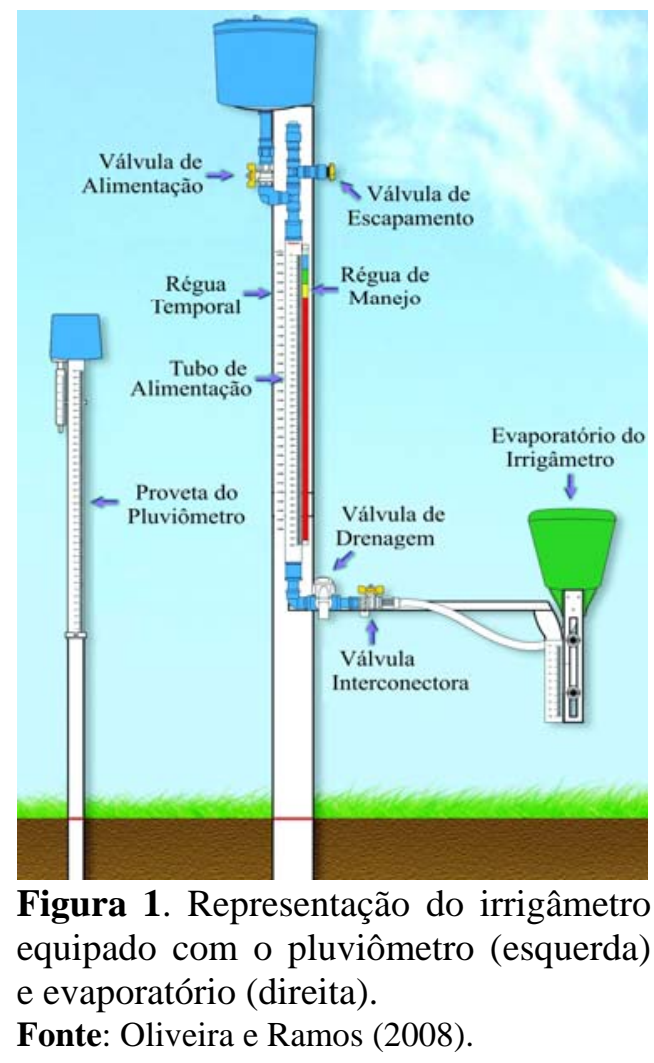

\section{MATERIAL E MÉTODOS}

O experimento foi conduzido no lote 72, área D do Perímetro Irrigado do Jaíba, Jaíba, MG, situada a $15^{\circ} 36^{\prime}$ de latitude Sul e $43^{\circ} 42^{\prime}$ ' de longitude Oeste, com altitude de $460 \mathrm{~m}$. O lote agrícola é de propriedade da CODEVASF (Companhia de Desenvolvimento dos Vales do São Francisco e do Parnaíba), a qual desenvolve no local um projeto para treinamento de jovens agricultores com apoio da EMATER-MG. O solo foi classificado como Neossolo Quartzarênico, segundo o Sistema Brasileiro de Classificação de Solos, com baixa capacidade de retenção de água cultivado com girassol irrigado com aspersão convencional. Os valores médios obtidos com cinco repetições para capacidade de campo e ponto de murcha permanente foram 5\% e 3\%, respectivamente, obtidos pelo método do extrator de Richards (Richards, 1951), e densidade do solo igual a $1,70 \mathrm{~g} \mathrm{~cm}^{-3}$, obtida pelo método do anel volumétrico (EMBRAPA, 1979).

A evapotranspiração de referência foi calculada com base nos dados da estação automática do INMET, localizada a uma distância de 1,5 km da área experimental. A estação meteorológica de superfície automática é composta de uma unidade de memória central ("data logger"), ligada a vários sensores dos parâmetros meteorológicos (pressão atmosférica, temperatura e umidade relativa do ar, precipitação, radiação solar, direção e velocidade do vento), que integra os valores observados minuto a minuto e, automaticamente, a cada hora. Foi utilizada a equação de Penman-Monteith FAO 56 para dados horários de temperatura máxima e mínima do ar, radiação solar, umidade relativa do ar e velocidade do vento, conforme as recomendações de Allen et al. (1998).

Para este experimento foram usados seis Irrigâmetros, cada aparelho foi ajustado numa altura diferente, de tal forma que os níveis da água no interior do evaporatório foram de 1, 2, 3, 4, 5, e $6 \mathrm{~cm}$. A coleta de dados foi realizada entre os dias 6 de junho e 4 de agosto de 2008.

Neste trabalho foi proposta uma alteração na metodologia utilizada por Tagliaferre (2006) para cálculo do $\mathrm{K}_{\mathrm{I}}$, em que esse parâmetro é determinado diariamente pela razão entre a evapotranspiração estimada pelo Irrigâmetro $\left(\mathrm{ET}_{\mathrm{I}}\right)$ e a evapotranspiração de referência $\left(\mathrm{ET}_{0}\right)$ 
OLIVEIRA, E. M.; OliVEIRA, R. A.; PAUlA, A. L. T.; BAPTESTINI, J. C. M.; CAIXETA, S. P.; GIOVANELLI, L. B. Desempenho do irrigâmetro no manejo da irrigação no Perímetro Irrigado do Jaíba, MG, Brasil. Ambi-Agua, Taubaté, v. 6, n. 1, p. 157-164, 2011. (doi:10.4136/ambi-agua.181)

estimada pelo método de Penman-Monteith FAO 56. Atribuiu-se então ao $\mathrm{K}_{\mathrm{I}} \mathrm{o}$ valor do coeficiente angular $\left(\beta_{1}\right)$ da regressão linear entre o total dos valores de $\mathrm{ET}_{\mathrm{I}}$ e $\mathrm{ET}_{0}$ obtidos durante o experimento (Rocha et al., 2003). Com essa metodologia, o coeficiente linear ( $\left.\beta_{0}\right)$ é igual a zero (Medeiros et al., 2004). Para isso, utilizou-se a Equação 1 para o cálculo do coeficiente linear.

$$
K_{I}=\frac{\sum E T_{0} \cdot E T_{I}-\frac{\left(\sum E T_{0}\right)\left(\sum E T_{I}\right)}{n}}{\sum E T_{0}^{2}-\frac{\left(\sum E T_{0}\right)^{2}}{n}}
$$

em que:

$\mathrm{K}_{\mathrm{I}}$ - coeficiente do Irrigâmetro, adimensional;

$\mathrm{ET}_{\mathrm{I}}$ - estimativa da evaporação da cultura no Irrigâmetro, $\mathrm{mm} \mathrm{d}^{-1}$;

$\mathrm{ET}_{0}$ - evapotranspiração de referência, $\mathrm{mm} \mathrm{d}^{-1}$; e

n - número de pares de dados, adimensional.

Para avaliar o manejo da irrigação utilizou-se a produtividade da cultura do girassol como indicador (Silva et al., 2007). Foram diferenciadas 20 parcelas experimentais, 10 irrigadas no período diurno e 10 irrigadas no período noturno, com o objetivo de avaliar o efeito da irrigação nos dois períodos do dia sobre a produtividade do girassol. Os dados de produtividade foram analisados por meio de análise de variância e as médias comparadas utilizando-se o Teste de Tukey ao nível de 5\% de probabilidade

O turno de rega foi diário, considerando-se a baixa capacidade de retenção de água do solo $(6,8 \mathrm{~mm})$ e a profundidade radicular efetiva $(0,20 \mathrm{~m})$. Sabe-se que a determinação do turno de rega e da quantidade de água a ser aplicada na irrigação é decisiva para o sucesso da intensificação das produções das culturas principalmente nas condições citadas (Alencar, 2007; Leitão e Oliveira, 2000).

Para separar as parcelas em dois períodos de irrigação foram instaladas duas linhas principais, uma pressurizada no período diurno e outra no período noturno. O sistema de irrigação por aspersão foi montado de forma a aplicar uma lâmina de aplicação baixa $\left(1,1 \mathrm{~mm} \mathrm{~h}^{-1}\right)$, simultaneamente nas parcelas submetidas ao mesmo tratamento. Cada parcela experimental foi composta de 12 linhas de plantio com média de 15 plantas em cada linha, resultando em, aproximadamente, 180 plantas de girassol por parcela.

Os valores do coeficiente (Tabela 1) de cultura foram de 0,4 para as fases inicial e final e de 1,1 para a fase intermediária, de acordo com as recomendações realizadas por Allen et al. (1998).

Tabela1. Estádios de desenvolvimento da cultura do girassol, duração dos estádios e os coeficientes de cultura.

\begin{tabular}{lcc}
\hline Fases ou estádios & Coeficiente de cultura (Kc) & Duração da fase (dias) \\
\hline Inicial & 0,40 & 15 \\
Desenvolvimento & 0,75 & 25 \\
Intermediário & 1,10 & 35 \\
Final & 0,40 & 15 \\
\hline
\end{tabular}

Fonte: Allen et al. (1998).

A colheita do girassol foi realizada manualmente, e para o cálculo da produtividade de sementes de girassol, considerou-se ajuste do peso para a umidade de $12 \%$ em base seca. 
OLIVEIRA, E. M.; OlIVEIRA, R. A.; PAUlA, A. L. T.; BAPTESTINI, J. C. M.; CAIXETA, S. P.; GIOVANELLI, L. B. Desempenho do irrigâmetro no manejo da irrigação no Perímetro Irrigado do Jaíba, MG, Brasil. Ambi-Agua, Taubaté, v. 6, n. 1, p. 157-164, 2011. (doi:10.4136/ambi-agua.181)

\section{RESULTADOS E DISCUSSÃO}

As equações de regressão ajustadas (Figura 2) estabelecem a relação entre os valores de evapotranspiração estimados por cada Irrigâmetro $\left(\mathrm{ET}_{\mathrm{I}}\right)$ e a $\mathrm{ET}_{0}$, com valor nulo $\beta_{0}$. Assim, o valor de $\mathrm{K}_{\mathrm{I}}$ corresponde ao valor do coeficiente angular $\beta_{1}$.

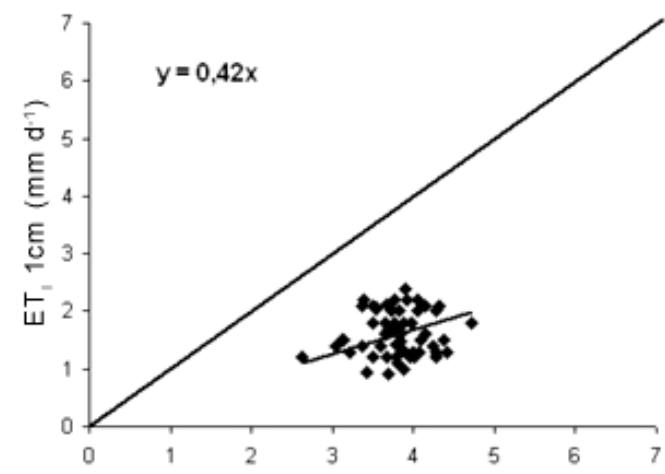

(a) ETo $\left(\mathrm{mm} \mathrm{d}^{-1}\right)$

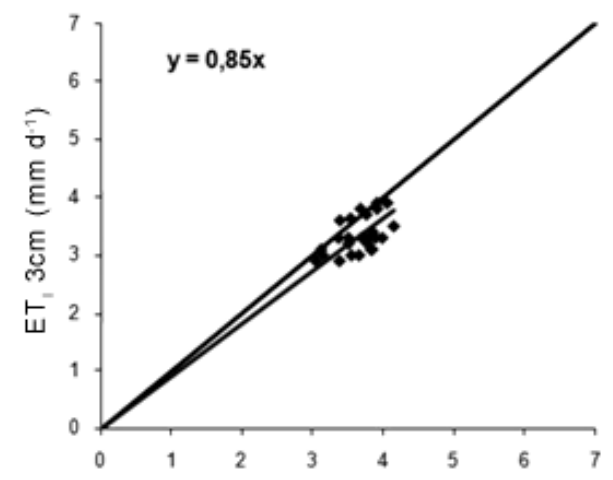

(c) ETo $\left(\mathrm{mm} \mathrm{d}^{-1}\right)$

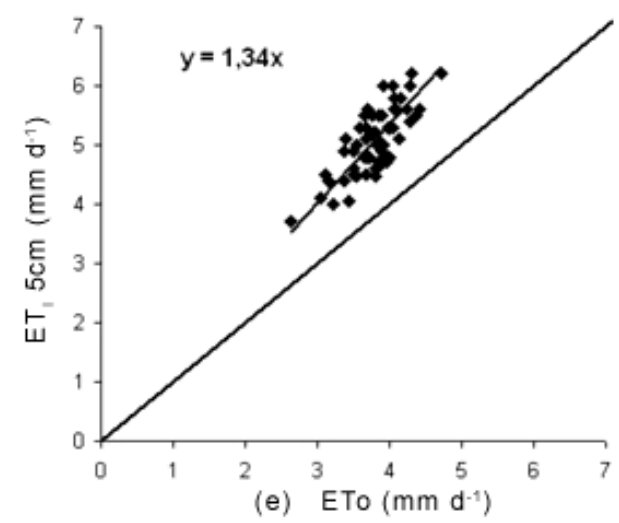

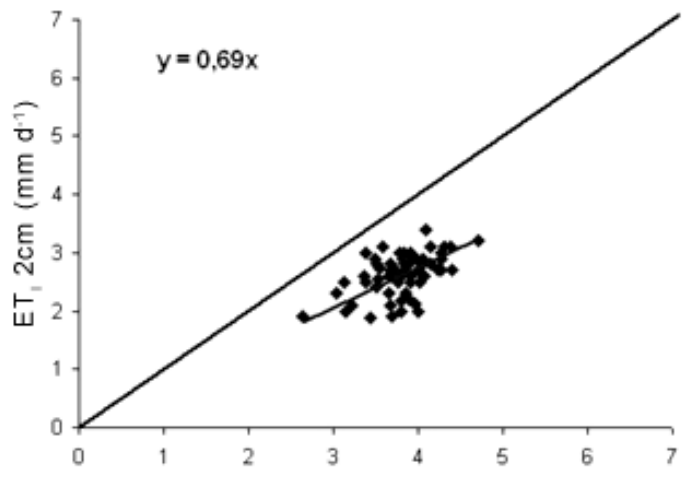

(b) ETo $\left(\mathrm{mm} \mathrm{d}^{-1}\right)$

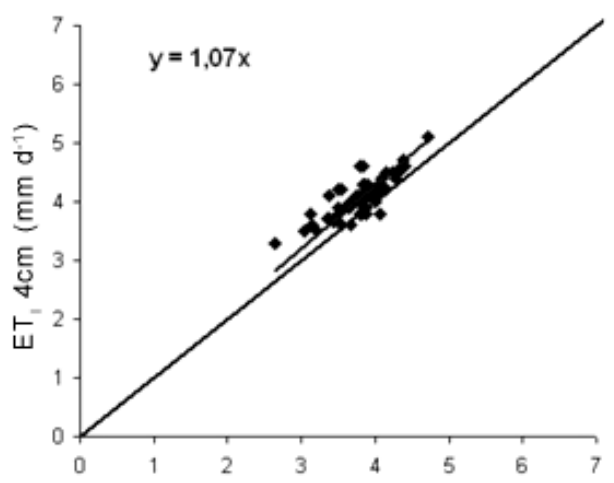

(d) ETo $\left(\mathrm{mm} \mathrm{d}^{-1}\right)$

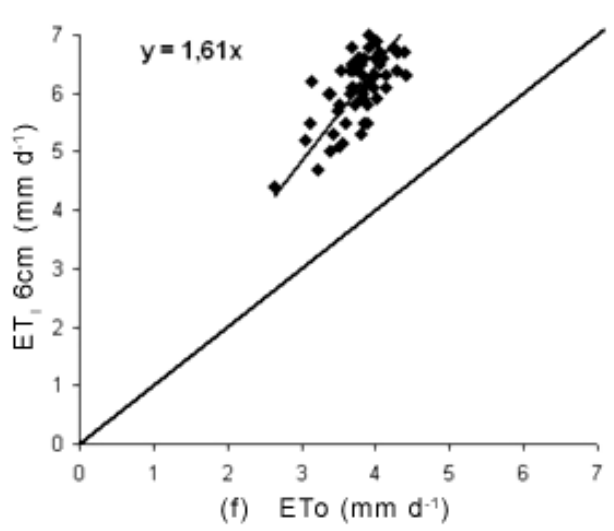

Figura 2. Relação entre a $\mathrm{ET}_{0}$ estimada pelo método Penman-Monteith FAO 56 e a $\mathrm{ET}_{\mathrm{I}}$ nos níveis de água iguais a 1, 2, 3, 4, 5 e 6 cm no evaporatório.

Os valores de $K_{I}$ obtidos por meio das equações ajustadas foram $0,42,0,69,0,85,1,07$, 1,34 e 1,61 para os Irrigâmetros com níveis de água no evaporatório de 1, 2, 3, 4, 5 e 6 cm respectivamente. Esses valores se aproximaram dos valores obtidos utilizando o método proposto por Tagliaferre (2006), que foram 0,40, 0,68, 0,86, 1,09, 1,36 e 1,60. Dessa forma não se identificou vantagem no uso da metodologia proposta. Diferenças entre as metodologias podem ser melhor identificadas em estudos mais longos e com maiores amplitudes climáticas. 
OLIVEIRA, E. M.; OliVEIRA, R. A.; PAUlA, A. L. T.; BAPTESTINI, J. C. M.; CAIXETA, S. P.; GIOVANELLI, L. B. Desempenho do irrigâmetro no manejo da irrigação no Perímetro Irrigado do Jaíba, MG, Brasil. Ambi-Agua, Taubaté, v. 6, n. 1, p. 157-164, 2011. (doi:10.4136/ambi-agua.181)

Na Figura 2, observa-se a relação entre a evapotranspiração estimada pelo Irrigâmetro, com nível da água no evaporatório ajustado nas diversas alturas, e a evapotranspiração obtida pelo método padrão de Penman-Monteith FAO 56 ao longo do período experimental.

A regressão linear de primeira ordem, apresentada na Figura 3, resulta numa equação com coeficiente de determinação igual a 0,994.

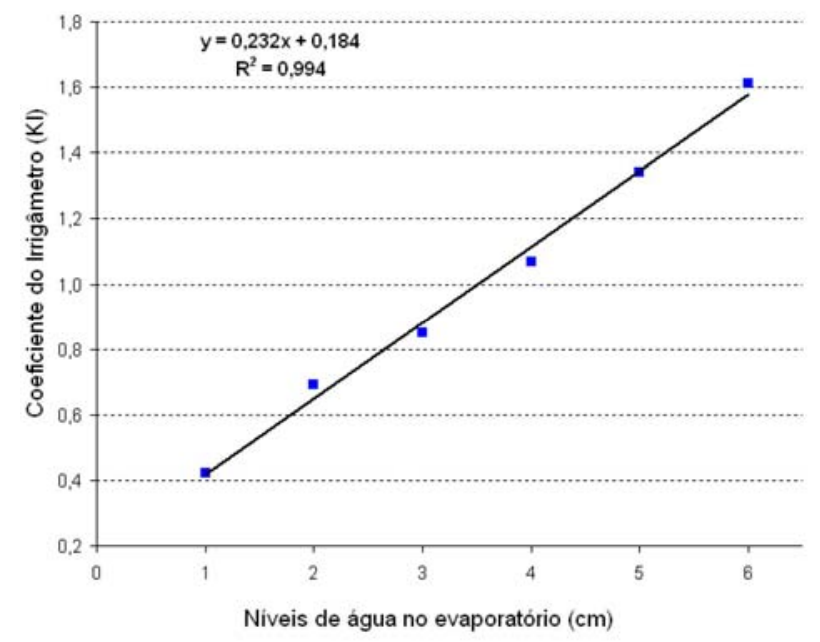

Figura 3. Valores médios do coeficiente do Irrigâmetro $\left(\mathrm{K}_{\mathrm{I}}\right)$ para as diferentes alturas do nível de água no evaporatório.

De acordo com a equação de primeira ordem ajustada aos dados, recomenda-se, para a utilização do Irrigâmetro na estimativa da $\mathrm{ET}_{0}$, manter o nível de água no evaporatório em 3,7 $\mathrm{cm}$, valor correspondente ao $\mathrm{K}_{\mathrm{I}}$ igual a 1 .

Observa-se na Figura 4 que os valores de evapotranspiração estimados pelo Irrigâmetro ajustado no nível de $4 \mathrm{~cm}$, acompanharam de forma mais precisa as mudanças nos valores da $\mathrm{ET}_{0}$ ao longo do período de medição. Os níveis 5 e $6 \mathrm{~cm}$ superestimaram a evapotranspiração de referência, enquanto os níveis 1 , 2 e 3 cm subestimaram.

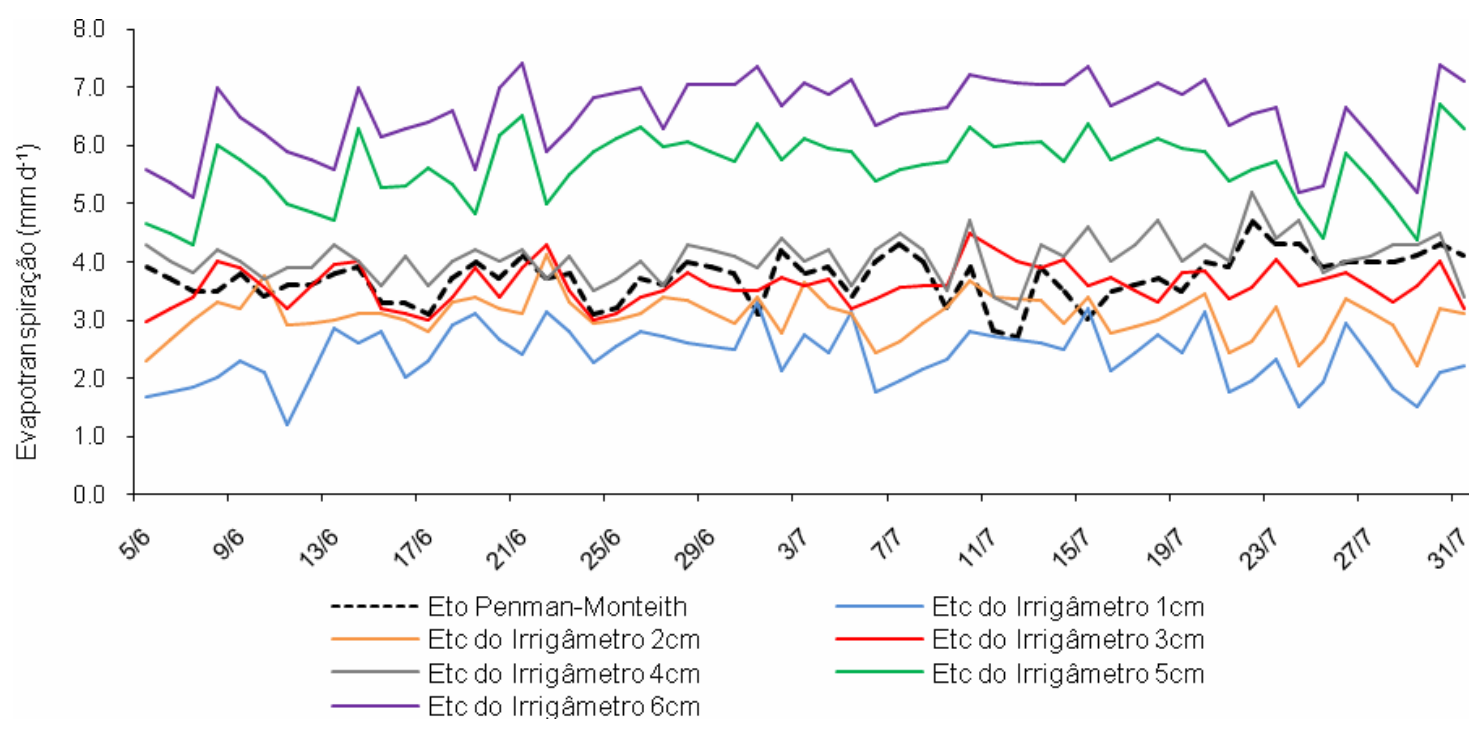

Figura 4. Valores de evapotranspiração estimada pelo Irrigâmetro com nível da água no evaporatório nas alturas 1, 2, 3, 4, 5 e $6 \mathrm{~cm}$ e da $\mathrm{ET}_{0}$, ao longo do período experimental.

A produtividade média do girassol para a irrigação no período diurno foi de $6.143 \mathrm{~kg} \mathrm{ha}^{-1}$ e para o período noturno foi de $6.281 \mathrm{~kg} \mathrm{ha}^{-1}$. A aplicação do teste entre as médias de 
OLIVEIRA, E. M.; OliVEIRA, R. A.; PAUlA, A. L. T.; BAPTESTINI, J. C. M.; CAIXETA, S. P.; GIOVANELLI, L. B. Desempenho do irrigâmetro no manejo da irrigação no Perímetro Irrigado do Jaíba, MG, Brasil. Ambi-Agua, Taubaté, v. 6, n. 1, p. 157-164, 2011. (doi:10.4136/ambi-agua.181)

produtividade mostrou que estas não diferem significativamente ao nível de $5 \%$ de probabilidade (Tabela 2).

Tabela 2. Produtividade média da cultura do girassol irrigado nos períodos diurno e noturno.

\begin{tabular}{cc}
\hline Períodos & Produtividade $\left(\mathbf{k g ~ h a}^{-\mathbf{1}}\right)$ \\
\hline Diurno & $6.143^{\mathrm{a}}$ \\
Noturno & $6.281^{\mathrm{a}}$ \\
\hline
\end{tabular}

*As médias seguidas pela mesma letra para cada tratamento não diferem estatisticamente entre si ao nível de $5 \%$ de probabilidade pelo teste de Tukey.

Considerando os dois períodos, o valor médio de produtividade de $6.212 \mathrm{~kg} \mathrm{ha}^{-1}$ foi $100 \%$ superior à obtida por EMBRAPA (2007) e Resende et al. (2006) para o mesmo genótipo, na mesma região e em solo semelhante. Considerando essas semelhanças nas condições de cultivo do girassol, o aumento de produtividade observado no presente trabalho pode ser atribuído ao manejo adequado da irrigação.

\section{CONCLUSÃO}

1. Os valores de $K_{I}$ obtidos foram 0,42, 0,69, 0,85, 1,07, 1,34 e 1,61 para alturas do nível de água do evaporatório iguais a 1, 2, 3, 4, 5 e 6 cm, respectivamente.

2. O uso do irrigâmetro mostrou-se satisfatório no manejo da irrigação da cultura do girassol e para obter a estimativa da evapotranspiração de referência nas condições climáticas da região do Jaíba, MG, recomenda-se a utilização do Irrigâmetro equipado com evaporatório ajustado no nível $3,7 \mathrm{~cm}$.

\section{REFERÊNCIAS}

ALENCAR, C. A. B. Produção de seis gramíneas forrageiras tropicais submetidas a diferentes lâminas de água e doses de nitrogênio, na região leste de Minas Gerais. 2007. 125 f. Tese (Doutorado) - Universidade Federal de Viçosa, Viçosa, MG, 2007.

ALLEN, R. G.; PEREIRA, L. S.; RAES, D.; SMITH, M. Guidelines for computing crop water requeriments. Rome: FAO, 1998. 310p. (Irrigation and drainage Paper, 56)

BESKOW, S.; COLOMBO, A.; RIBEIRO, M. S.; FERREIRA, L. S.; ROSSI, R. Simulação das perdas de água por evaporação e arraste, no aspersor NY-7 (4,6 mm x 4,0 mm), em sistemas de aspersão convencional. Engenharia Agrícola, Jaboticabal, v. 28, n. 3, p. 427-437, jul./set., 2008.

CONTIN, F. S. Tecnologia do irrigâmetro aplicada no manejo da irrigação do feijoeiro. 2008. 62 f. Dissertação (Mestrado em Engenharia Agrícola) - Universidade Federal de Viçosa, Viçosa, MG, 2008.

EMPRESA BRASILEIRA DE PESQUISA AGROPECUÁRIA - EMBRAPA. Indicações para o cultivo de girassol nos Estados do Rio Grande do Sul, Paraná, Mato Grosso do Sul, Mato Grosso, Goiás e Roraima. Londrina: EMBRAPA Soja, 2007. (Boletim Técnico, Fev. 2007).

EMPRESA BRASILEIRA DE PESQUISA AGROPECUÁRIA - EMBRAPA. Manual de métodos de análise de solo. 2. ed., rev. atual. Rio de Janeiro: Centro Nacional de Pesquisa de Solos, 1979. 212 p. (EMBRAPA-CNPS, Documento1). 
LEITÃO, M. M. V. B. R.; OLIVEIRA, G. M. Influência da irrigação sobre o albedo. Revista Brasileira de Engenharia Agrícola e Ambiental, Campina Grande, v. 4, n. 2, p. 214218, 2000.

MEDEIROS, G. A.; ARRUDA, F. B.; SAKAI, E. Relações entre o coeficiente de cultura e cobertura vegetal do feijoeiro: erros envolvidos e análises para diferentes intervalos de tempo. Acta Scientiarum, Maringá, v. 26, n. 4, p. 513-519, 2004.

OLIVEIRA, E. M.; OLIVEIRA, R. A.; BAPTESTINI, J. C. M. Ajuste do irrigâmetro para estimar a evapotranspitação da cultura, por meio da variação da área do evaporatório. In: SIMPÓSIO DE INICIAÇÃO CIENTÍFICA, 12., Viçosa, MG, 2007 Anais... Viçosa, MG: UFV, 2007a. 1 CD-ROM.

OLIVEIRA, E. M.; OLIVEIRA, R. A.; TAGLIAFERRE, C.; SEDYIAMA, G. C. Ajuste do irrigâmetro para estimar a evapotranspitação da cultura nos seus diversos estádios de desenvolvimento. In: CONGRESSO NACIONAL DE ENGENHARIA AGRÍCOLA, 36., 2007, Bonito. Anais... Bonito: SBEA, 2007b. 1 CD-ROM.

OLIVEIRA, R. A.; RAMOS, M. M. Manual do irrigâmetro.Viçosa, MG: UFV, 2008. 144 p.

OLIVEIRA, R. A.; TAGLIAFERRE, C.; SEDIYAMA, G. C.; MATERAN, F. J. V.; CECON, P. R. Desempenho do irrigâmetro na estimativa da evapotranspiração de referência. Revista Brasileira de Engenharia Agrícola e Ambiental, Campina Grande, v. 12, n. 2, p. 166-173, 2008.

RESENDE, J. C. F. de, PACHECO, D. D.; PIMENTEL, R. M. A.; SANTOS, D. A.; SOARES, J. F. Características de híbridos de girassol no norte de Minas Gerais. Janaúba: EPAMIG - Centro Tecnológico do Norte de Minas, 2006.

RICHARDS, L. A. Methods of measuring soil moisture tension. Soil Science Of American Journal, Baltimore, n. 68, p. 95-112, 1951.

ROCHA, O. C.; GUERRA, A. F.; AZEVEDO, H. M. Ajuste do modelo ChistiansenHargreaves para estimativa da evapotranspiração do feijão no cerrado. Revista Brasileira de Engenharia Agrícola e Ambiental, Campina Grande, v. 7, n. 2, p. 263268, 2003.

SATO, F. A.; SILVA, A. M.; COELHO, G.; SILVA, A. C.; CARVALHO, L. G. Coeficiente de cultura $(\mathrm{kc})$ do cafeeiro (coffea arabica l.) no período de outono-inverno na região de Lavras - MG. Engenharia Agrícola, Jaboticabal, v. 27, n. 2, p. 383-391, mai./ago. 2007.

SILVA, M. L. O.; FARIA, M. A.; MORAIS, A. R.; ANDRADE, G. P.; LIMA, E. M. C. Crescimento e produtividade do girassol cultivado na entressafra com diferentes lâminas de água. Campina Grande, PB. Revista Brasileira de Engenharia Agrícola e Ambiental, v. 11, n. 5, p. 482-488, 2007.

TAGLIAFERRE, C. Desempenho do irrigâmetro e de dois minievaporímetros para estimativa da evapotranspiração de referência. 2006. 99 f. Tese (Doutorado em Engenharia Agrícola) - Universidade Federal de Viçosa, Viçosa, MG, 2006.

TAGLIAFERRE, C. Geração de tecnologia inovadora aplicada ao Irrigâmetro para o manejo racional da água de irrigação. 2007. 50 f. Relatório (Pós-Doutorado) Universidade Federal de Viçosa, Viçosa, MG, 2007. 